Descentramentos/ convergências. Ensaios de crítica feminista

Rita Terezinha Schmidt Porto Alegre: Editora

da UFRGS, 2017.

\section{La crítica feminista bajo el signo del comparatismo}

\author{
Rafael Eisinger Guimarães • \\ Universidade de Santa Cruz do Sul
}

El trabajo de Rita Terezinha Schmidt ha sido crucial para la formación de por lo menos dos generaciones de feministas y comparatistas en Brasil. Gracias a su trayectoria, hoy podemos afirmar que tanto la crítica feminista y los estudios de género como la literatura comparada son campos de investigación consolidados en los programas de posgrado brasileños. Este protagonismo, por sí solo, justificaría la expectativa alrededor de la publicación de la colección de ensayos Descentramentos/convergências. Una expectativa que acaba siendo superada, con sobras, por las lectoras y por los lectores que hojean sus más de 400 páginas.

Aliado a la mirada lúcida, profunda y transdisciplinaria que dirige a las relaciones entre mujer, literatura y cultura, el estilo contundente y al mismo tiempo cautivante de su escritura hace de los 20 textos que componen la obra una lectura tan placentera como imprescindible. Dividido en dos partes, el libro reúne materiales que circularon anteriormente en periódicos, libros y anales de eventos realizados dentro y fuera de Brasil, en un período que va del final de los años 1980 a la segunda década del siglo XXI. En función de esa amplitud cronológica, Descentramentos/convergências ofrece una profunda discusión de algunas de las cuestiones más contundentes en el debate académico, no sólo en lo que se refiere a la crítica feminista, sino también en lo que concierne a los estudios comparatistas y literarios de modo general. Entre ellos se destacan el proceso de construcción del femenino como un signo de la cultura patriarcal a partir de relaciones simbólicas de poder, la discusión de la validez de las teorías feministas de matriz anglófona y francófona para un contexto poscolonial, el desvelamiento de los presupuestos políticos e ideológicos detrás de los criterios de valor que orientan la elaboración del canon literario y el papel de las historias literarias nacionales, marcadamente androcéntricas, en la construcción de una identidad cultural que coloca el femenino al margen de la nación.

\footnotetext{
- Doctor en Literatura Comparada en el Programa de Posgrado en Letras de la Universidad Federal de Río Grande do Sul (UFRGS), Brasil. Profesor-investigador en el Departamento de Letras y en el Programa de Posgrado en Letras de la Universidad de Santa Cruz do Sul (UNISC), Brasil. Se interesa por las áreas de Literatura Brasileira e Literatura Comparada, con énfasis en los estudios poscoloniales, crítica feminista y estudios de género (gender studies).
} 
Después de un texto inicial, en el que se introducen las principales cuestiones discutidas en el resto de la obra, tales como la figuración de lo femenino en la literatura de autoría masculina y el rescate crítico de la producción literaria de las mujeres, Rita Schmidt, en los tres ensayos subsecuentes, reflexiona sobre el proceso de instauración y consolidación de la crítica feminista en Brasil, a partir de los ańos 1980, destacando no sólo el impacto y la resistencia que tales cuestiones teóricas causaron al desembarcar en tierras brasileñas, así como los cambios epistemológicos derivados del advenimiento, por ejemplo, de la categoría de género, de la perspectiva post-estructuralista y de la apertura de los estudios a la teoría queer. Concluyendo el primer bloque, sigue una serie de ensayos en que se discuten algunas de las problematizaciones más amplias que guiaron la trayectoria de la autora, tales como el cuestionamiento de la mal disimulada perspectiva ideológica que sostiene la construcción del canon y de la historiografía literaria, el rescate de la producción de las escritoras brasileńas del siglo XIX silenciadas por el discurso crítico y académico patriarcal, la cuestión de la autoría femenina, entre otros temas.

Tal preocupación con cuestiones teórico-políticas más amplias se mantiene como telón de fondo de los ensayos que componen la segunda parte del libro, sumándose a ella un conjunto de análisis más puntuales, en las que se discuten no sólo obras de autoría femenina, con destaque para nombres como los de Clarice Lispector, Lya Luft, Kate Chopin y Virginia Woolf, entre otras, como también novelas escritas por figuras masculinas consideradas canónicas por la crítica literaria, entre las cuales Machado de Assis, Gustave Flaubert, Leon Tolstoi y James Joyce. En estos textos, más que una mirada que articula rigor teórico y sensibilidad crítica, encontramos ejemplos de un ejercicio de reflexión en que parece no haber fronteras entre el feminismo y el comparatismo. 